\title{
Impact of Downsizing on Employee Commitment and turnover intentions in Public and Private Sector: Moderating role of social support
}

\author{
Dr. Naveed Iqbal Chaudhry ${ }^{1}$ \\ Dr. Irfana Shah ${ }^{2}$ \\ Dr. Hakim Ali Mahesar ${ }^{3}$ \\ Usman Tariq ${ }^{4}$
}

\begin{abstract}
Due to economic crisis, organizations all over the world are adopting a number of different schemes to handle emerging problems. Downsizing or retrenchment of employees is frequently used by organizations when they face hardships at the marketplace. Under these circumstances, lack of commitment is the most crucial counter action which organizations have to face. This study intends to examine the impact of downsizing on organizational commitment and turnover intentions of surviving employees in the moderating role of social support. The target audience for this study was four public and private sector organizations located in Islamabad. The sample size consisted of 333 employees of upper and middle level management which were selected through simple random sampling. The result shows that downsizing is positively related to employee turnover intention and has significant negative impact on employee commitment. However, social support as a moderator enhanced employee commitment. This study will help the managers to comprehend when and how to apply downsizing so as not to harm the employee's commitment. The study will further assist managers to implement downsizing and social support to achieve the objectives.
\end{abstract}

Keywords: Downsizing, Employee Commitment, Turnover intentions, and Social support

\section{INTRODUCTION}

In the 90s the economic crisis jolted almost every country and organization of the world. Organizations all over the world adopted a number of different schemes to handle the problems produced by the economic crunch. One of the most common ways adopted by most of the organizations was downsizing. Downsizing or retrenchment of employees is frequently used by the organizations when they suffer any losses whether it is financial or managerial (Ko \& Yeh, 2013). Many world class companies like General Motors, American Express, Dell, DuPont, and Apple computers along with many other companies have undergone some type of downsizing and remained successful. But in some cases downsizing didn't help to achieve the desired results. Downsizing influence the wellbeing of a firm in number of ways, i.e. the productivity of the organization, its environment, employee's satisfaction and commitment etc. (Chen \& Kao, 2012; Gautam, Van Dick, \& Wagner, 2004). Organizational downsizing comprises a bunch of activities that are intended to improve organizational competence (Freeman \& Cameron, 1993). The prime objective of the organizations is to minimize cost and maximize profit. Due to the economic recession business organizations faced many problems that affect profitability. To achieve organizational goals in unfavorable situation organization

1- Dr. Naveed Iqbal Chaudhry is Assistant Professor at University of the Punjab, Gujranwala, naveed.iqbal@pugc.edu.pk

2- Dr. Irfana Shah is Assistant Professor, Department of Psychology at University of Sindh, Jamshoro,

irfana_shah_irfanashah@yahoo.com

3- Dr. Hakim_Ali Mahesar is Assistant

4- Usman Tariq is M.Phil. Scholar at Quaid-e-Azam University, Islamabad, usmanntariqq@gmail.com

JISR-MSSE

Volume 13

Number 2

July-Dec 2015 
opt the downsizing strategy and cut down their workforce while improving the efficiency, productivity and competitiveness as well as to reduce the employee volume and diminishing the cost and expenses.

Past studies reveal that downsizing might affect organization commitment because when organizations radiate their workforce, they rely on the left over employees. This increases the workload on the survivors and they do not remain loyal with the organization because of fear of losing their jobs in the times to come (Lee \& Corbett, 2006). After economic recession the emerging concept of downsizing has paved a new way of research in the field of organizational change. These studies have generally focused on the western companies that have undergone downsizing. Global economic recession and financial crisis have also affected Pakistani organizations, which in order to compete in the global market and to cope with the problems have also adopted downsizing strategy (Shah \& Hasnu, 2013). Pakistani organizations face many problems, i.e., uncertainty, and war on terror which are not been faced by the western economies and due to these problems Pakistani organizations lose their market and as a result take corrective measures and one of them is downsizing. Due to loss of business and market share fear of job insecurity is developed among employees that significantly influence the employees' commitment towards organization. The research is scanty and invites academicians and researchers to add local aroma so that solution can be sought. In this scenario it is necessary to address downsizing phenomenon in the eastern environment.

The purpose of this paper is to provide a brief insight into the impact of downsizing on the commitment of employees and organization in Pakistan and how downsizing affects turnover intentions of surviving employees. It actually explored how downsizing can affect the level of surviving employees' dedication, loyalty and assurance towards their job. It also analyzed the moderating role of social support of the employees and tries to find out how this variable affects employees commitment in Pakistani context. This paper anticipates and explores the relationship between downsizing and turnover intention. The reason behind exploring this relationship was to assess and evaluate the difference between the effect produced by downsizing on turnover intention in developing and developed countries. Besides giving a comprehensive view on impact of downsizing on employees' commitment, this paper also intends to help the managers to increase the employee's performance by applying downsizing as and when required.

\section{LITERATURE REVIEW}

\section{Downsizing and Employee Commitment}

Organizational downsizing is deliberate reduction of organizational resources i.e. physical, financial and human resources. It consists of activities that are being held in an organization to increase the efficiency and productivity of the organization (Freeman and Cameron, 1993). Downsizing always creates tough scenario for the employees as companies trim their workforce so that creativity, teamwork and strength could be enhanced by retaining committed and hardworking employees (Amiable \& Conti, 2014). It is a useful strategy for decreasing cost by cutting down workforce in order to enhance organizational performance. Commitment is generally characterized as acceptance of organizational goals by employee, the willingness to exert force for the sake of organization and the desire to remain part of the organization (Lemons \& Jones, 2001). A committed employee always prefer organization's interest and drive their personal interests from them therefore, employee is likely to work more effectively and also remains loyal with the organization (Romzek, 1990). 
Downsizing can have both positive as well as negative effects on the commitment of employees. Those affected by downsizing without proper communication at proper time perceive it in a negative way and view downsizing as unethical (Ko \& Yeh, 2013; Tu \& Yang; Wang, Sang, Li, \& Zhao). It is stated that the timing, method and content of downsizing are very important that determine the perception of employees regarding downsizing thus affecting the overall employee's commitment and loyalty towards the organization. According to Cameron (1994) implementation of work force reduction during hard economic times may be necessary but short term payoffs may not be very appropriate. When the implicit employment contract is violated then it brings loss of loyalty among the surviving workforce and they may hesitate to work efficiently.

Organizations which undergo downsizing want their remaining employees to take on the work of those who have deceased. According to past researchers, the employees who are survivors of downsizing have decreased organizational commitment (Brockner, Tyler, Grover, Reed, Cooper-Schneider, 1992; Brockner, Wiesenfeld, Reed, Grover, Martin, 1990). This loss of commitment becomes more severe if the employees identify themselves closely with those who have left. It means that commitment of employees decreases if they view downsizing as unjust. Past studies show that mostly firms engage in downsizing because of external changes and poor organizational performance (Hussain, Fareed, \& Shahzad, 2014). Hence, it is believed that if a firm wants to improve its profit, it can cut down its expenses by eliminating its workforce. However, downsizing may cause a negative effect on the behaviors and attitudes of the survivors (Sheaffer, Carmeli, Steiner-Revivo, \& Zionit, 2009). Nevertheless, it's a fact that decreasing workforce creates stressful environment for survivors.

It is observed that survivors may assess downsizing as a loss of their co-workers and also can experience the change in workload. The change in work can be positive or negative with respect to whether a survivor perceives it as a threat or an opportunity. The increased quantity of work is a threat for a worker but the increase in job task or autonomy is the opportunity for her or him (Surienty, Ramayah, Lo, \& Tarmizi, 2014). If negative changes devastate the positive changes then it will decrease the employee's commitment (Lee and Corbett, 2005) According to Noor (1993), when workforce is reduced intentionally because of causes other than performance then this is generically termed as layoffs or termination and these intentional layoffs results in phenomena called "layoff survivor sickness". In this type of sickness the employee who is the sufferer develops certain attitudes, beliefs and feelings about the organization and these specific attitudes and beliefs result in loss of commitment and risk adverse behavior in employees (Noor, 1992).

Burke and Nelson (2009) explained survivor syndrome as multiple kinds of behaviors and emotions which the employees exhibit after organizational downsizing. These behaviors and emotions may constitute low productivity, increased absenteeism, job dissatisfaction, slowness etc. The past study explained that survivors lose their interest in the job which leads to reduced job satisfaction (Campbell and Paper, 2006). On the other hand, it is also a possibility that employee's commitment may get enhanced after the process of downsizing. This can occur because the left over employees after downsizing may feel that they have an importance and that their work is being considered important in the organization (Appelbaum and Donia, 2001).

Employees are an integral part of any organization and play an important role in the success and achievement of organizational goals. Employees committed to the organization perform efficiently and provide a competitive edge to the organization. Employee commitment is defined as 'to the extent a person identifies with and works towards organization' (Noble and 
Mokwa, 1999, p. 61; Paris and Busch, 2008). It is also explained as the psychological attachment of the employees with their organization. Past studies revealed that a single factor model is insufficient to explain employee's commitment, thus a multidimensional approach is proposed (Meyer and Allen, 1991; Cross \& Travaglione, 2004). Meyer and Allen (1991) proposed a three component model of employee commitment. It is further explained affective commitment as the emotional acceptance of organizational goals and continuous commitment explains the awareness of the cost in leaving an organization while normative commitment reflects to a feeling of being part of an organization (Carmeli \& Gefen, 2005).

Employee commitment has many positive outcomes on the organization (Dessler, 1999). The most important work out comes of commitment is on job behavior of employees. An employee engaged with his organization tends to avoid absenteeism and perform competently towards the accomplishment of organizational objectives (Zimmerman \& Darnold, 2009). The relationship between downsizing and employee's commitment can also be judged by the way in which downsizing process is carried out. The employees who survived the process perceived it as fair \& just and their commitment and attachment with the organization increases. However, if they perceive it as unjust then their productivity may get reduced. According to Gandolfi (2008) the survivors of downsizing view their future in the organization as uncertain and due to this uncertainty their commitment towards the organization decreases. So in order to make downsizing effective it must be conducted in a fair way.

\section{H1: There is a significant relationship between downsizing and employees commitment.}

\section{Employees' turnover intention}

Since the last few decades' turnover intention has captured the attention of scholars and HR practitioners, as they are interested to find out the reasons behind how and why employees leave their job (Price, 1977; Mobley, Griffeth, Hand, \& Meglino, 1979; Griffeth, Hom, \& Gaertner, 2000; Holtom, Mitchell, Lee \& Eberly, 2008). Turnover intention is actually the subjective intention of employees to leave the organization (Vandanberg and Nelson, 1999). There are many factors and reasons of employees' turnover intension. Whenever the employee is dissatisfied from his or her job she/he thinks to leave his or her job and get some other more reliable job. According to past studies there are no specific predicators or antecedents of turnover intention; however, there can be distal antecedents of turnover intention which can be job characteristics, personality etc. or there can be attitudinal antecedent which includes job satisfaction (Hom, Mitchell, Lee, \& Griffeth, 2012). Other antecedents can be job stress, quality of work life, organizational justice, commitment, age, tenure and marital status can also be the reason of turnover intention. Aryee and Chen (2002) stated that accumulation of negative feelings may also lead to an increase in turnover amongst employees. Downsizing is also one of the reasons of voluntary turnover (Moody, 2000). When organizations carry out downsizing process it strongly affects the surviving employees. Employees commitment and loyalty towards their organization decrease, which may result in job dissatisfaction, job stress and other negative behaviors. These negative behaviors affect the attachment of the employee towards his organization and also impact his performance organization (Mostert, Rothmann \& Nell, 2008). After downsizing the survivor employees become insecure and start considering other employment options. Due to downsizing larger layoffs occur and employees become instable (Moody, 2000). Studies depict that after downsizing employees who are best performers tend to leave the organization and try to get a more secure job (Godkin and St. Pierre, 1999). 
H2: There is a significant relationship between downsizing and employees turnover intentions.

\section{Role of social support as moderators}

The moderating effects of social status (Kidd and Green, 2006) are helpful in studying different behaviors and their direct or indirect influence on commitment of employees. Commitment of employees with organization is related to several personal factors of the employees, e.g., age, gender, tenure and social support of employee (Bateman and Strasser, 1984). Social support consists of emotional and materialistic resources which an individual can utilize when needed in stress situation (Cohen and Thoits, 1995). Social support can have positive as well as negative impact. Social support plays a role of moderator between downsizing and organizational commitment. Greater the social support lower will be the impact of downsizing on survivors commitment towards organization. Social support also enrich the sense of accountability in employees to help the organization in attaining their goals, it also increases their affective commitment towards organization and their expectation that their efforts will be rewarded.

The results of social support are context dependent and the conditions in which social support is provided govern its impact (Beehr et al. 2003). It means that social support during downsizing can dilute the negative impact of downsizing on commitment. Social support comes from different sources and this support effects job satisfaction in different ways (Seers, McGee, Serey and Graen, 1983). When social support increases job satisfaction, it directly influences the commitment of employees with his job and organization.

\section{H3: Social support moderates the relationship between downsizing and employee commitment}

The literature suggests that there are conflicting findings regarding the relationship between downsizing and employees commitment. Moreover, past researches depict that results very according to the context in which those studies were conducted. Therefore, this study is intended to explore the phenomena in the context of Pakistan.

\section{CONCEPTUAL MODEL}

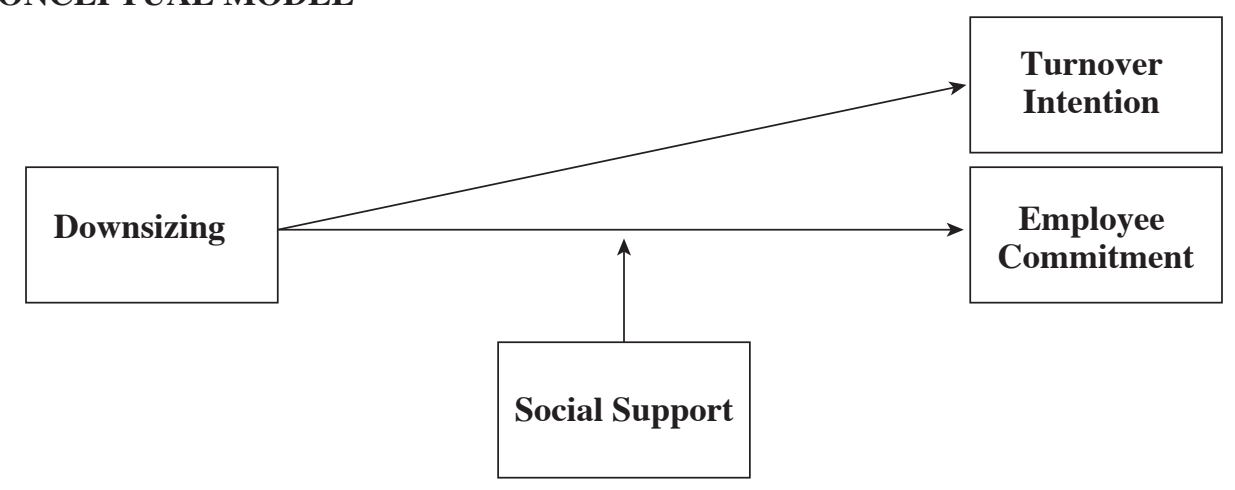




\section{RESEARCH METHODOLOGY}

The population of this study consists of public and private large organizations located in Islamabad. The target population is comprised of three organizations, two companies from telecom sector, and one company from aviation sector, i.e., Mobilink, Ericson, and PIA respectively located in Islamabad. The sample size of this study consists 333 employees from the above mentioned three organizations $(n=333)$ of Mobilink, Ericson and PIA Islamabad. The simple random sampling technique was applied for primary data collection in this study as it was easy and hassle free. In this sampling technique the respondents have equal chance of selection from the population.

\section{Instrument}

Questionnaire based survey was used for collecting the primary data from the respondents. The questionnaire was selected as instrument because it gives exact and accurate data. The questionnaire was developed keeping in mind the variables and literature and the purpose of the research. Questionnaire was consisted of demographic section and 34 items of downsizing, turnover intention, organizational commitment and social support.

\section{Measurement}

The various variables in this study were measured by using different scales. Downsizing was measured by selecting six items from a scale developed by Hussain et al., (2014). All the questions were measured using five point Likert scale. Employee's effective commitment towards their organization was measured by using six items from a scale developed (Meyer and Allen, 1997). This scale is reliable and valid for measuring commitment. Five point Likert scale was also used for measuring the responses of the respondents. Turnover intention was measured by using six items from a scale of Viator (2001). All the questions were measured using five point Likert scale. Employee's perception about their organization's support and the extent to which their supervisor appreciate their contribution and support measured by using items from Survey of Perceived Organizational Support (SPOS) developed (Eisenberger et al., 1986). The scale was further validated (Stinglhamber \& Vandenberghe, 2003). For this variable respondents were asked to rate their agreement with each statement using a 5-point Likert-type scale ( $1=$ strongly disagree; $4=$ stands for disagree, $3=$ is equal to neutral, $2=$ stands for agree and $5=$ strongly agree).

\section{Procedure}

The study selected three companies such as Mobilink, Ericson and PIA to collect primary data. Questionnaires were distributed to a random sample of 350 survivor employees in organizations located in Islamabad Pakistan and have recently undergone downsizing. However, 333 were properly filled. The sample includes all the managerial level employees of the above mentioned companies. The employees of the three companies, i. e., Mobilink, Ericson and PIA were personally approached and the purpose of the study was explained to them. After briefing session the respondents raised certain questions and they were addressed by the research team members. Once the respondents concerns were settled the questionnaires were distributed among them. Each employee was given one questionnaire only and each employee was asked to fill at the spot in the presence of the research team. This research was a team effort therefore, each member was allocated one company and he/she was responsible to collect data from that organization. The organizations were selected carefully and only those organizations were included who have gone through downsizing. Those employees and organizations were in a position to compare and explain the downsizing phenomenon comprehensively. This measure was taken to get accurate data from the employees. 


\section{RESULTS AND DISCUSSION}

For analyzing our research results we entered the data into SPSS and AMOS about downsizing, organizational commitment, social support and turnover intention. To elaborate the findings we have applied multiple tests to the data such as Descriptive Statistics, Reliability or Cronbach Alpha, Model Fitness Tests, Pearson Correlation, Regression and Moderating Effect Test by Andrew F. Hayes.

Table-1

\begin{tabular}{llcc}
\hline \multicolumn{3}{c}{ Data Reliability } \\
\hline S. No & Variable & N & Cronbach alpha \\
\hline 1 & Downsizing & 333 & 0.937 \\
2 & Employee Commitment & 333 & 0.963 \\
3 & Turnover Intention & 333 & 0.945 \\
4 & Social support & 333 & 0.918 \\
\hline
\end{tabular}

The table-1 illustrates the values of Cronbach's alpha that tells about the reliability of the data collected regarding variables such as downsizing, social support, turnover intention and organizational commitment values $0.937,0.918,0.945$ and 0.963 respectively. These figures indicate that the instrument that we used for our research is highly reliable as reliability is greater than 0.70 . The value of data reliability $(0.70)$ is accepted and it is explained and verified by Frost \& Stauffer (2007).

Table-2

Correlation

\begin{tabular}{|c|c|c|c|c|}
\hline \multicolumn{5}{|c|}{ Correlations } \\
\hline & & Downsizing & $\begin{array}{c}\text { Employee } \\
\text { Commitment }\end{array}$ & Turnover intention \\
\hline & $\begin{array}{l}\text { Pearson Correlation } \\
\text { Sig. (2-tailed) }\end{array}$ & & & \\
\hline \multirow[t]{2}{*}{ Downsizing } & $\mathrm{N}$ & 333 & & \\
\hline & $\begin{array}{l}\text { Pearson Correlation } \\
\text { Sig. (2-tailed) }\end{array}$ & $\begin{array}{l}-.426^{* *} \\
.000\end{array}$ & & \\
\hline \multirow[t]{2}{*}{ EmpComt } & $\mathrm{N}$ & 333 & 333 & \\
\hline & $\begin{array}{l}\text { Pearson Correlation } \\
\text { Sig. (2-tailed) }\end{array}$ & $\begin{array}{l}.697 * * \\
.000\end{array}$ & $\begin{array}{l}.176^{*} \\
.026\end{array}$ & \\
\hline TOI & $\mathrm{N}$ & 333 & 333 & 333 \\
\hline
\end{tabular}

**. Correlation is significant at the 0.01 level (2-tailed).

*. Correlation is significant at the 0.05 level (2-tailed). 
The table-2 illustrates the Pearson Correlation among variables. The correlation values of downsizing for turnover intention is 0.697 and $\mathrm{p}$ value ( $\mathrm{p} .000)$ is significant that means turnover intention and downsizing are significantly correlated while correlation value of downsizing for organizational commitment is -0.426 that also depicts the significant relation among variables but a negative one.

Table-3

Regression

\begin{tabular}{ccccc}
\hline \multicolumn{5}{c}{ Model Summary } \\
\hline Model & $\mathbf{R}$ & R Square & Adjusted R Square & Std. Error of the Estimate \\
\hline 1 & $.697 \mathrm{a}$ & .485 & .482 & .89122 \\
2 & $-.426 \mathrm{a}$ & .181 & 176 & .89561 \\
a.Predictors: (Constant), Down Sizing & & \\
\hline
\end{tabular}

b.Dependent Variable: TOI

c.Dependent Variable: EC

The table-3 explains the linear regression analysis that was applied to check the impact of downsizing on turnover intention and organizational commitment with Durbin-Watson. The total change in dependent variable (Organizational commitment \& Turnover intention) is explained by $\mathrm{R}$ square due to the impact of independent variables (Downsizing). The table is showing the value of 0.697 for downsizing and turnover intention that depicts that downsizing can bring $69 \%$ change in turnover intention. Meanwhile for the relationship between downsizing and organizational commitment showing the value of $\mathrm{R}$ square about -0.426 concluding that downsizing can bring $42 \%$ negative change in organizational commitment.

Table- 4

Regression Coefficient

\begin{tabular}{llccc}
\hline \multicolumn{3}{c}{ Coefficients } \\
\hline Variable & $\begin{array}{l}\text { Standardized } \\
\text { Co-efficient } \\
\text { Beta }\end{array}$ & t value & F value & Sig \\
& .697 & 4.864 & 148.904 & .000 \\
Turnover Intention & -.426 & 5.863 & 35.029 & .000 \\
Employee Commitment & & & & \\
\hline
\end{tabular}

The individual impact of independent variable on dependent variable is described by beta values highlighted in the above table. The beta value of turnover intention is 0.697 which is depicting that downsizing can increase the chances of turnover intention by $69 \%$. Thus the hypothesis $\mathrm{H} 1$ is accepted. Downsizing can reduce organizational commitment by $42 \%$ as its value is -.426 for standardized beta so $\mathrm{H} 2$ is also approved. The coefficient beta value for turnover intention and employee commitment are 0.697 and 0.426 , t values 4.864 and 5.863, and $F$ value 148.904 and 35.029 respectively. The table-4 also describes that for all dependent variables $t$ values are greater than 2 and $F$ values are greater than 4 . Both values depict that downsizing and both dependent variables, i.e., turnover intention and social support are positively and significantly correlated. The value of significance for turnover intention and organizational commitment respectively is .000 which is less than 0.05 however it illustrate that downsizing is strongly related with both turnover intention and organizational commitment. 
Table-5

Moderation Test

$\mathrm{Y}=$ Employee Commitment

$\mathrm{X}=$ Downsizing

$\mathrm{M}=$ Social Support

\begin{tabular}{lllllll}
\hline & coeff & Se & T & P & LLCI & ULCI \\
\hline Constant & 2.2037 & .0551 & 40.0214 & .0000 & 2.0949 & 2.3125 \\
Socialspprt & 2.5571 & .0748 & 34.1812 & .0000 & 2.4094 & 2.7049 \\
DownSize & -1.5869 & .0745 & -21.3070 & .0000 & -1.7341 & -1.4398 \\
Int_1 & .0952 & .0341 & 2.7919 & .0059 & .0278 & .1625 \\
\hline
\end{tabular}

To check the impact of moderating variables that is social support in our research, Andrew F. Hayes test is used in the above table. Results showed that for int_1, the value of P is 0.0059 , which is less than 0.05 so it enlightened that social support moderate the relationship between downsizing and organizational commitment.

\section{DISCUSSION}

The research study shown that there is a significant relationship between downsizing with both turnover intention and Organizational commitment as it has been tested through the correlational and regression tests. The values of Pearson correlation states that all the variables under study are significantly correlated but the relation between downsizing and turnover intention was more stronger than the relationship between downsizing and the organizational commitment illustrated by the values of correlation and $\mathrm{R}$ square which were 0.697 and -0.426 respectively. Furthermore the ANOVA value for the relationship was also significant as it has been showing the value .000 which is less than 0.05 . The fact has also been supported by the values of beta from the regression table. The coefficient beta value for turnover intention and employee commitment are 0.697 and -0.426 , $t$ values 4.864 and 5.863, and $F$ value 148.904 and 35.029 respectively. Both values depict that downsizing is positively linked with the turnover intention but negatively linked with employee commitment. The fact is also supported by the past studies as past studies depicts the negative relationship between downsizing and employee commitment (Meyer \& Stanley 2002, Nyasha at el., 2014). Thus, based on the analysis and findings both of the hypotheses are accepted.

Whereas there was moderating effect which was tested through a process test designed by Andrew F. Hayes shown that of social support found significant relationship between downsizing and employee commitment due to the interaction significance value which was lesser than 0.05. It is also supported by the study of Laschinger \& Finegan (2001) that due to the social support organizational commitment and downsizing has significant relationship. Hence, hypothesis 3 was accepted.

\section{CONCLUSION}

The basic objective of this study was to check the impact of downsizing on employees' turnover intention and employee commitment, with the moderating role of social support in the relationship of downsizing and employee commitment. This study shows that downsizing may hold a significant position when it comes to cost cutting during economic recession, but it also adversely effects the performance of an organization. H1 was proved correct and accepted, which clearly shows that downsizing directly effects the turnover intentions of surviving employees, i.e surviving employees loses their attachment towards organization and become insecure so, they start looking for new job opportunities.

\begin{tabular}{llll}
\hline JISR-MSSE & Volume 13 & Number 2 & July-Dec 2015 \\
\hline 43
\end{tabular}


This research also depicts that downsizing significantly affects employee commitment towards their organization thus; accepting H1 which is in accordance with past studies, as past studies shows that downsizing negatively effects employee commitment (Marques at el., 2014, Luthans \& Sommer 1999). This study also proved the role of social support as a moderator in the relationship of downsizing and employee commitment, which shows acceptance of hypothesis 3. As it shows that if employees have their supervisors and organization's support where there efforts are appreciated and they can participate in organization's decision, their commitment towards their organizations increases which ultimately enhances their performance and dedication towards their work. Thus, this study shows that downsizing strategy adopted as a cost cutting method may be effective for a short period, but in long run it can have adverse effects, as it may increases the turnover intentions of employee or can affect their commitment also. However, social support can help the employers to keep their employees committed to their organization by appreciating and communicating with them (Allen \& Shanock 2013, Lynch \& Eisenberg, 1999).

\section{PRACTICAL IMPLICATIONS}

This research work has theoretical and practical implications. Theoretically it extends the research in the field of downsizing, how downsizing is beneficial for an organization and how it affects its employees. There is no past study carried out on analyzing the relationship of downsizing and employee turnover intention. Moreover, it also enlightened the importance of social support in mediating the relationship between downsizing and employee commitment, and enhancing commitment. Practically this study will help managers to carry out downsizing process carefully, keeping in view possible reactions from employees and the ways those reactions can be mitigated. Social support in the form of supervisor support can keep the employees committed even during downsizing, which will eventually improve organizational performance. Strategy should be developed to decrease the turnover intention of surviving employee.

\section{LIMITATIONS AND FUTURE RESEARCH}

The sample of this study was very small due to various constraints. The future research may take larger sample size. Furthermore, the sample was taken from three companies only which do not give a complete picture. The future researcher may include greater number of companies. This study was conducted in three organizations which have undergone downsizing process, as total population can't be accessible due to lack of resources and time. Future research may be conducted on larger level to have a holistic view. Moreover, the research study do not consider age, job tenure, social status, justice and communication, as they can be important moderating factors in the case of employee commitment and turnover intentions. Future research can also focus on difference between organizational culture of public and private sector organizations, as it also affects the employee commitment and turnover intention. 


\section{REFERENCES}

Allen, D. G., \& Shanock, L. R. (2013). Perceived organizational support and embeddedness as key mechanisms connecting socialization tactics to commitment and turnover among new employees. Journal of Organizational Behavior, 34(3), 350-369.

Amabile, T. M., \& Conti, R. (1999). Changes in The Work Enviornment for Creativity During Downsizing. The Academy of Management Journal Vol. 42, No.6, 630-640.

Carmeli, A., \& Gefen, D. (2005). The relationship between work commitment models and employee withdrawal intentions. Journal of Managerial Psychology Vol. 20 No. 2, 63-86.

Chen, Chun-hsi Vivian, \& Kao, Rui Hsin. (2012). Work values and service-oriented organizational citizenship behaviors: The mediation of psychological contract and professional commitment: A Case of Students in Taiwan Police College. Social indicators research, 107(1), 149-169.

Cross, B., \& Travaglione, A. (2004). The times they are a-changing: who will stay and who will go in a downsizing organization? Personal Review, Vol. 33, No.3, 275-290.

Dessler, G. (1999). How to Earn Your Employees' Commitment. The Academy of Management Executive, Vol. 13, No.2, 58-67.

Freeman, S. J., \& Cameron, K. S. (Feb 1993). Organizational Downsizing: A Convergence and Reorientation Framework. Organization Science, Vol. 4, No. 1, 10-29.

Frost, M. H., Reeve, B. B., Liepa, A. M., Stauffer, J. W., \& Hays, R. D. (2007). What Is Sufficient Evidence for the Reliability and Validity of Patient-Reported Outcome Measures? Value in Health, 10(s2), S94-S105.

Gautam, Thaneswor, Van Dick, Rolf, \& Wagner, Ulrich. (2004). Organizational identification and organizational commitment: Distinct aspects of two related concepts. Asian Journal of Social Psychology, 7(3), 301-315.

Godkin, L and J. St. Pierre. 1999. How not to reap the whirlwind of bank downsizing. Journal of retail banking services 21 (1, Spring): 47-49

Hom, P. W., Mitchell, T. R., Lee, T. W., \& Griffeth, R. W. (2012). Reviewing employee turnover: focusing on proximal withdrawal states and an expanded criterion. Psychological bulletin, 138(5), 831.

Hopkins, S. M., \& Weathington, B. L. (2006). The relationships between justice perceptions,trust, and employee attitudes in a downsized organization. The Journal of Psychology, 140(5), 477-498.

Hussain, S., Nayyab, H., Fareed, Z., Ahmad, H., \& Shahzad, F. (2014). Exploring downsizing: a case study of airline company of Pakistan. International Journal of Accounting and Economics Studies, 2(2), 88-94. 
Inbal Nahum-Shani, P. A., \& Bacharach, S. B. (2011). Social Support and Employee Well-Being: The Conditioning Effect of Perceived Patterns of Supportive Exchange. Journal of Health and Social Behavior, Vol. 52, No. 1, 123-139.

Ko, Jyh-Jer Roger, \& Yeh, Ying-Jung Yvonne. (2013). Worker satisfaction following employment restructuring: Effects of nonstandard workers and downsizing on job satisfaction in Taiwan. Social indicators research, 110(2), 453-467.

Laschinger, H. K. S., Finegan, J., \& Shamian, J. (2001). The impact of workplace empowerment, organizational trust on staff nurses' work satisfaction and organizational commitment. Health Care Management Review, 26(3), 7-23.

Lee, J., \& Corbett, J. (2006). The Impact of Downsizing on Employees' Effective Commitment. Journal of Managerial Psychology Vol. 21 No. 3.

Lemons, M. A., \& Jones, C. A. (2001). Procedural justice in promotion decisions: using perceptions of fairness to build employee commitment. Journal of Managerial Psychology, Vol.16, No.4, 268-280.

Luthans, B. C., \& Sommer, S. M. (1999). The impact of downsizing on workplace attitudes differing reactions of managers and staff in a health care organization. Group \& Organization Management, 24(1), 46-70.).

Lynch, P. D., Eisenberger, R., \& Armeli, S. (1999). Perceived organizational support: Inferior versus superior performance by wary employees. Journal of Applied Psychology, 84(4), 467.).

Marques, T., Galende, J., Cruz, P., \& Portugal Ferreira, M. (2014). Surviving downsizing and innovative behaviors: a matter of organizational commitment. International Journal of Manpower, 35(7), 930-955.

McDevitt, R., Giapponi, C., \& Houston, D. M. (2013). Organizational Downsizing During an Economic Crisis:Survivors' and Victims' Perspectives. Organization Management Journal Vol. 10, No. 4, 227-239.

Meyer, J. P., Stanley, D. J., Herscovitch, L., \& Topolnytsky, L. (2002). Affective, continuance, and normative commitment to the organization: A meta-analysis of antecedents, correlates, and consequences. Journal of vocational behavior, $61(1), 20-52$.

Moody, R. W. 2000. Going, going, gone. The internal auditor 57 (3, June): 36-41

Nyasha, M., Martin, C., Pride, M., Justice, M., Piason, M., \& Edson, V. (2014). Impact of Downsizing on Employee Commitment: A Case Study of Surface and Mashwede Refinery. International Journal of Innovative Research and Development, 3(7).

Parish, J. T., Cadwallader, S., \& Busch, P. (2008). Want to, need to, ought to: employee commitment to organizational change. Journal of Organizational Change Management Vol. 21, No,1, 32-52. 
Parish, J. T., Cadwallader, S., \& Busch, P. (2008). Want to, need to, ought to: employee commitment to organizational change. Journal of Organizational Change Management Vol. 21, No,1, 32-52.

Romzek, B. S. (1990). Employee Investment and Commitment: The Ties That Bind. Public Administration Review, Vol.50, No.3, 374-382.

Shah, S. S., \& Hasnu, S. A. (2013). Effect of Job Instability on Job Performance: Banking Sector of Pakistan. Journal of Asian Development Studies, Vol. 2, No. 1, 93-106.

Sheaffer, Z., Carmeli, A., Steiner-Revivo, M., \& Zionit, S. (2009). Downsizing strategies and organizational performance: A Longitudinal Study. Management Decision, Vol. 47, No.6.

Stinglhamber, F., \& Vandenberghe, C. (2003). Oragnizations and Supervisors as Sources of Support and Targets of Commitment:A Longitudinal Study. Journal of Organizational Behavior, Vol. 24, No. 3, 251-270.

Surienty, Lilis, Ramayah, T, Lo, May-Chiun, \& Tarmizi, Azlin Natasha. (2014). Quality of work life and turnover intention: a partial least square (PLS) approach. Social Indicators Research, 119(1), 405-420.

Tu, Yangjun, \& Yang, Zhi. Self-Control as Mediator and Moderator of the Relationship Between Social Support and Subjective Well-Being Among the Chinese Elderly. Social Indicators Research, 1-16.

Vandenberg, R. J. and J. B. Nelson. 1999. Disaggregating the motives underlying turnover intentions : When do intentions predict turnover behavior? Human relations 52 (10): 1313-1336

Wang, Pengyuan, Sang, Jinyan, Li, Ping, \& Zhao, Jian. How to Make a Newcomer Happy? The Mediating Role of Career Commitment on the Relationship Between Unmet Expectations and Job Satisfaction. Social Indicators Research, 1-12.

Zimmerman, R. D., \& Darnold, T. C. (2009). The impact of job performance on employee turnover intentions and voluntary turnover process. Personnel Review, Vol. 38, No.2, 142-158. 